\title{
Economic Efficiency in Indian Rubber Industry
}

\author{
Sarba Priya Ray
}

\begin{abstract}
The article tries to assess the utilization efficiency of capacity of Indian rubber industry in terms of econometric framework for the period,1979-80 to 2008-09.Capacity output has been obtained at the minimum point of short run average cost curve. The result suggests that there has been declining growth rate of capacity utilization in rubber industry of India during the post reforms period accompanied by declining output growth as well as capacity growth. There exists some excess capacity in the rubber industry which remains unutilized during our study period. The result exhibits that high correlation coefficient between actual output and capacity output for Indian rubber sector implies that major part of under utilization of capacity is intended and low correlation between capacity expansion (CE) and past utilization(CUL) seems to suggest that under utilization, if any, is mainly of the unintended nature, capacity expansions do not move in line with past utilization rates and it also indicates that abolition of restrictions on licensing due to trade liberalization do not help industry to expand capacity. On the other hand, low correlation between capacity expansion (CE) and lagged output (QL) indicates that unintended excess capacity is varying from year to year in an unsystematic matter.
\end{abstract}

KEY WORDS: $\quad$ capacity, utilization, growth, rubber, industry, India.

JEL Classification: D23, L65

${ }^{1}$ university of Calcutta, India

\section{Introduction}

A much overestimated claim without much empirical validation is that trade liberalization opens up new opportunities for enhancing investment as well as productivity, capacity utilization and promoting quality improvement vis-a-vis competitiveness in export markets arising from value added exports. However, the launching of trade reforms and liberalisation policies under the WTO mandated trade policy regime has seriously affected the Indian plantation sector in general and the rubber production sectors in particular. One of the most explicit impacts of the trade liberalisation

Corespondence concerning to this article should be addressed to: sarbapriyaray@yahoo.com policies had been the emergence of market uncertainties leading to a fall in the international and domestic prices of commodities caused by the removal or dilution in tariff and non-tariff protective barriers. The magnitude of decline in prices from the peak levels reported during the decade 1990-2001 has been the highest for rubber (42\%). The instability in prices (expressed as coefficient of variation (CV) from the peak level prices) has also been the highest for rubber (26\%) [Viswanathan, 2005].

The decline in commodity prices triggered its adverse effects on the rubber production and trade sectors leading to an unprecedented crisis in plantation agriculture in India. In the case of rubber, the liberal trade policy reforms have resulted in removal of quantitative restrictions (QRs) which in turn enabled the 

capital outlay and at the same time generates employment opportunities without involving additional capital expenditure. It is also true that where there is underutilization of capacity, there is ample scope of utilizing capital more extensively by increasing working shifts in the industry. Nevertheless, a major lacuna in this engineering approach is that it does not explain the variations in capacity utilization mainly due to lack of any economic foundation.

The economic approach, on the other hand, defines the potential output as being the optimum level of output from the economic point of view. This alternative considers capital as a quasi fixed input and allows for distinction between short and long run cost curves. In the long run, capital can be adjusted in order to achieve optimal (cost minimizing/ profit maximizing ) level. In the short run, capital is fixed and only the variable inputs can be varied. The short run equilibrium output, for a competitive firm, is then given by the equality between exogenous output price and the short run marginal cost curve (SRMC), $\mathrm{Y}^{*}$. The potential output would then correspond to that level of output at which short run average total cost (SRATC) is minimized- $\mathrm{Y}^{* \star}$ ( and equal to long run average total cost,LRATC).

The definition of output as $\mathrm{Y}^{\star *}$ corresponds to the cost-minimization problem while $\mathrm{Y}^{*}$ corresponds to the profit-maximization. As pointed out in Berndt, \& Morrison(1981), this difference can affect short run equilibrium in the sense that it may or may not occur at the level of output were the SRATC reaches its minimum: $\mathrm{Y}^{\star}>\mathrm{Y}^{\star *}$ OR $\left(\mathrm{Y}^{*}<\mathrm{Y}^{\star *}\right)$ when the output price greater than (lower than) the minimum level of SRATC. The authors address also the issue of how variations in input prices might affect the minimum point of the SRATC and hence $\mathrm{Y}^{* *}$.

The economic approach was first analyzed by Cassels(1937) and latter on two more definitions have been introduced. The first was suggested by Klein(1960) and Friedman(1963) and recently Segerson \& Squires(1990) who define the potential output as being the output level at which the long run and short run average total cost curves are tangent. Klein (1960) argued that long run average cost curve may not have a minimum and proposed the output level where the short run average cost curve is tangent to the long run average cost curve as an alternative measure of capac- ity output. This is also the approach adopted by Berndt and Morrison (1981). If technology exhibits constant return to scale, long run average cost curve is horizontal and the capacity level output is not defined, In this case, at the minimum point, the short run average cost curve is tangent to the long run average cost curve. This helps to determine the economic capacity output in the short-run. We prefer choice- theoretic model because it is firmly based in the behavioural concept of economic theory. The choice theoretic approach defines capacity output as the long run desired level of output given capital stock and input prices.

The second approach supported by Cassels (1937) and Hickman(1964) takes as reference the output level at which the short run average total cost curve reaches its minimum. Therefore, an economically more meaningful definition of capacity output originated by Cassel (1937) is the level of production where the firms long run average cost curve reaches a minimum. Cassel (1937) suggests that a firm's capacity output is the minimum of the long run average cost curve. Klein and Friedman suggest capacity output as that output level at which long run and short run average cost curves are tangent. Economic capacity is a short run concept. The fixed nature of some inputs like capital characterizes short run. For any amount of fixed input like capital, the output which can be obtained with the minimum long run cost method is capacity output which will require a higher cost method of production and therefore short run average cost of output is above the long run average cost curve except at the capacity output level. In the short run, higher cost methods are required to obtain additional output since only variable inputs may be increased. Therefore, a firm with fixed capital may choose to operate in the short run at a level of output that differs from the long run desired level and variation in $\mathrm{CU}$ is viewed as a short run phenomenon due to quasi-fixity of capital.

As we consider the long run average cost, no input is held fixed. For a firm with the typical ' $U$ ' shaped average cost curve, at this capacity level of output, economies of scale have been exhausted but diseconomies have not set in. The physical limit defines the capacity of one or more quasi-fixed input. Klein (1960)defined capacity as the maximum sustainable level of output an industry can attain within a very short time, when not constrained by the demand for product and the 

it is quasi concave and also satisfies the conditions of monotonocity. Quasi-concavity required that the bordered Hessian matrix of first and second partial derivatives of the production function be negative semi definite.

$\mathrm{Y}=\mathrm{f}(\mathrm{K}, \mathrm{L}, \mathrm{E})$ where $\mathrm{K}, \mathrm{L}$ and $\mathrm{E}$ are capital, labour and energy respectively. Since capacity output is a short-run notion, the basic concept behind it is that firm faces short-run constraints like stock of capital .Firms operate at full capacity where their existing capital stock is at long-run optimal level. Capacity output is that level of output which would make existing short-run capital stock optimal.

Rate of $\mathrm{CU}$ is given as

$\mathrm{CU}=\mathrm{Y} / \mathrm{Y}^{*}$

$\mathrm{Y}$ is actual output and $\mathrm{Y}^{\star}$ is capacity output.

In association with variable profit function, there exist variable-cost functions which can be expressed as

$\mathrm{VC}=\mathrm{f}\left(\mathrm{P}_{\mathrm{L}}, \mathrm{P}_{\mathrm{E}}, \mathrm{K}, \mathrm{Y}\right)$

Short run total cost function is expressed as

$S T C=f\left(P_{L}, P_{E}, K, Y\right)+P_{K} \cdot K$

$\mathrm{PK}$ is the rental price of Capital.

Variable cost equation which is variant of general quadratic form for (2) that provide a closed form expression for $\mathrm{Y}^{\star}$ is specified as

$$
\begin{aligned}
& \mathrm{VC}=\alpha_{0}+\mathrm{K}_{-1}\left(\alpha_{\mathrm{K}}+1 / 2 \beta_{\mathrm{KK}}\left[\frac{\mathrm{K}-1}{\mathrm{Y}}\right]+\beta_{\mathrm{KL} .} \mathrm{P}_{\mathrm{L}}+\beta_{\mathrm{KE} .} \mathrm{P}_{\mathrm{E}}\right) \\
& +\mathrm{P}_{\mathrm{L}}\left(\alpha_{\mathrm{L}}+1 / 2 \beta_{\mathrm{LL}} \mathrm{P}_{\mathrm{L}}+\beta_{\mathrm{LE} .} \mathrm{P}_{\mathrm{E}}+\beta_{\mathrm{LY} .} \mathrm{Y}\right)+\mathrm{P}_{\mathrm{E}}\left(\alpha_{\mathrm{E}}+1 / 2 \beta_{\mathrm{EE}} \mathrm{P}_{\mathrm{E}}\right. \\
& \left.+\beta_{\mathrm{EY}} \mathrm{Y}\right)+\mathrm{Y}\left(\alpha_{\mathrm{Y}}+1 / 2 \beta_{\mathrm{YY} . \mathrm{Y}}\right)
\end{aligned}
$$

$\mathrm{K}_{-1}$ is the capital stock at the beginning of the year which implies that a firm makes output decisions constrained by the capital stock at the beginning of the year. Similar functional form has been previously estimated by Denny et al (1981). The variable cost function is based on the assumption that some input like capital cannot be adjusted to their equilibrium level. Therefore, the firm minimizes variable cost given the output and the quasi-fixed inputs.

Capacity output $\left(\mathrm{Y}^{\star}\right)$ for a given level of quasi-fixed factor is defined as that level of output which minimizes STC. So, the optimal capacity output level, for a given level of quasi-fixed factors, is defined as that level of output which minimizes STC. So, at the optimal capacity output level, the envelop theorem implies that the following relation must exist.

$$
\partial \mathrm{STC} \partial \mathrm{K}=\partial \mathrm{VC} / \partial \mathrm{K}+\mathrm{PK}=0
$$

In estimating $\mathrm{Y}^{\star}$, we differentiate VC equation (4) w.r.t $\mathrm{K}-1$ and substitute expression in equation (5)

$$
\mathrm{Y}^{*}=\frac{-\beta_{\mathrm{KK} .} \mathrm{K}_{-1}}{\left(\alpha_{\mathrm{K}}+\beta_{\mathrm{KL}} \mathrm{P}_{\mathrm{L}}+\beta_{\mathrm{KE}} \mathrm{P}_{\mathrm{E}}+\mathrm{P}_{\mathrm{K}}\right)}
$$

The estimates of $\mathrm{CU}$ can be obtained by combining equation (6) and (1).

\section{Description of data and variables}

It is the intricacy which is often faced by researchers in conducting studies on CU in Indian industries is that available official data on Industrial capacities are quite unsatisfactory. The present study is based on industry-level time series data taken from several issues of Annual Survey of Industries, NAS and Economic Survey ,Monthly statistics of foreign trade, Govt. of India, Statistical Abstracts (various issues), RBI bulletin, CMIE etc covering a period of 30 years commencing from $1979-80$ to $2008-09$. Selection of time period is largely guided by availability of data. Till $1988-89$, the classification of industries followed in ASI was based on the National Industrial classification 1970 (NIC 1970). The switch to the NIC-1987 from 1989-90 and also switch to NIC-1998 requires some matching. For price correction of variable, wholesale price indices taken from official publication of CMIE have been used to construct deflators.

\section{Output and Variable cost}

Output is measured as real value added produced by manufacturers (Y = PLL+ PK.K-1+ PE.E) suitably deflated by WIP index for manufactured product (base 1981-82 = 100) to offset the influence of price changes variable cost is sum of the expenditure on variable inputs (VC = PLL+ PE.E). Griliches and Ringstad (1971) have preferred GVA to gross output and reasons for imposing preference have been mentioned in their study. 

Where $r t$ is the rate of return on capital in year $\mathrm{t}, \mathrm{d} t$ is the rate of depreciation of capital in the year $t$

and $\frac{\mathrm{P}_{\mathrm{k}}}{\mathrm{P}_{\mathrm{k}}}$ is the rate of appreciation of capital.

Rate of return is taken as the rate of interest on long term government bonds and securities which is collected from RBI bulletin (various issues). Prime lending rate is generally viewed as an opportunity cost of capital, but problem is that there is no unique lending rate available for use. So, we have used rate of interest on long term government bond and securities as rate of return on capital [as previously used by Jha, Murty and Paul (1991)].Alternatively, one can use the gross yield on preferential industrial shares, if available, as Murty (1986) has done.

The rate of depreciation is estimated from the reported figures on depreciation and fixed capital as available in ASI which Murty (1986) had done earlier. However, we have not tried corrections for the appreciation of value of capital in the estimates of price of capital services. As Jorgenson and Griliches note capital gains should be deducted from $\left(\mathrm{r}_{\mathrm{t}}+\mathrm{d}_{\mathrm{t}}\right)$ but several studies have not done so and adjustment for capital gains does not seem to make much difference to the result.

\section{Analysis of capacity and its utilization}

In this section, we present the analysis of the results regarding measurement and trend in capacity utilization of rubber industry in India under our consideration. For easy comparison of the estimates, we have also subdivided the entire period into 1979-80 to 199192 which is termed as pre-reform period and 1991-92 to 2008-09 as post-reform period.

Initially, we have tries to depict the results of a multiple regression analysis applied to measure capacity output and the trend in capacity utilization. The variable cost equation shown as equation (4) has been estimated by the ordinary least square methods (OLS). Our model assumes that capacity utilization $(\mathrm{CU})$ is a function of input prices, output and quasi-fixed capital. We find that capacity utilization and input prices have a negative relationship and capacity utilization (CU) and output have a positive one. The derivative of VC (equation 4) with respect to $\mathrm{K}$ is negative since capital will substitute labour and energy. In order to test for the concavity of the variable cost function with respect to variable input prices, its Hessian matrix for negative semi-definiteness is evaluated and it is found that concavity condition is fulfilled at all observation points. Therefore, the partial derivative with respect to each of input prices is negative. The partial derivative of $\mathrm{VC}$ with respect to output is positive because in our empirical results, $\beta_{\mathrm{KK}}>0$ and $\left(\alpha_{\mathrm{K}}+\beta_{\mathrm{KL}} \mathrm{P}_{\mathrm{L}}+\beta_{\mathrm{KE}} \mathrm{P}_{\mathrm{E}}\right.$ $\left.+\mathrm{P}_{\mathrm{K}}\right)<0$ for all data points. Therefore, positive relation between output and capacity utilization (CU) is an indication that an increase in demand will lead to higher levels of capacity utilization.

The variations in capacity utilization in Indian rubber industry are presented in Table1. The key observations emerged out of the analysis of Table 1 are depicted below.

First, it has been obviously found from the estimated results that $\mathrm{CU}$ ratios are less than unity for all observations. There is a prominent diminishing trend in capacity utilization over years because average CU declined from 0.6608 in pre-reform period to 0.6154 in post-reform period implying a decline of $6.87 \%$ as well as same declining trend was set in average growth rate of $\mathrm{CU}$ ( as is evident from table 1,it declines from $2.71 \%$ in $1991-92$ to $-0.42 \%$ in $2008-09$ ). This implies that actual output fell far short of capacity output of Indian rubber industry which in turn signifies a widening difference between capacity output and actual output. Trend in capacity utilization indicates the presence of idle or excess capacity in the industry for the entire study period.

Second, if capacity output is taken to be the economic capacity derived from optimization process, the CU ratio could exceed one or it may be less than one. The implication of economic CU less than unity (as our result suggests) is that production is to the left of the minimum point of short-run average total cost curve which further signifies that Indian rubber sector could have reduced its short run generation costs with gradually moving to the tangency point or minimum point of the short run average cost curve.

Third, it is apparent from our study that the economic CU index ranges from about 0.5229 to 0.8202 . Capacity expansion varies from $10.08 \%$ to $4.66 \%$ during these two time frames.

Fourth, a comparison of the average utilization of capacity in the two periods (table-1 below) showed a 

Table 2. Trend Growth rate of capacity, output and capacity utilization

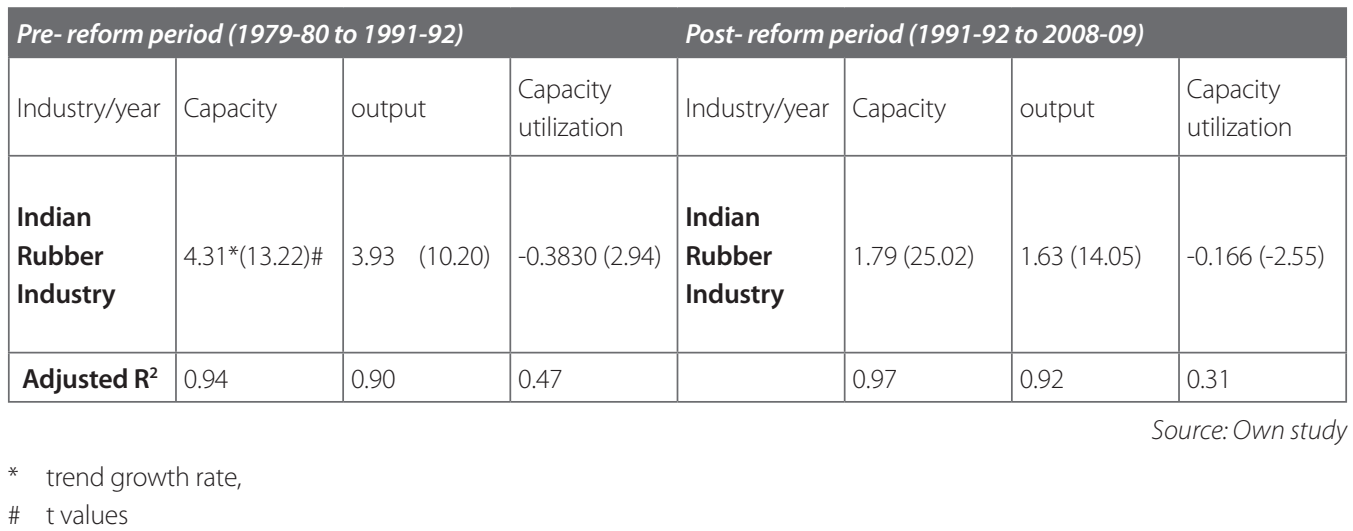

Table 3. Correlation Analysis

\begin{tabular}{|c|c|c|}
\hline Correlation between $C E$ and $C U_{L}$ & 1. Correlation between $C E$ and $Q_{L}$ & Correlation between $Q$ and $C Q$ \\
\hline 0.22 & 0.19 & 0.99 \\
\hline
\end{tabular}

Source: Own study

$\mathrm{CE}=$ Capacity expansion CQt - CQt-1

$\mathrm{CU}_{\mathrm{L}}=$ Lagged capacity utilization ratio $=\mathrm{CUt}-1$

$Q_{L}=$ Lagged production $=$ Qt-1

$\mathrm{Q}=$ observed output

$\mathrm{CQ}=$ capacity output

No. of observation $=25$ years.

Table 3 exhibits that correlation coefficient between actual output and capacity output is quite-high (0.99) for Indian rubber sector implying major part of under utilization of capacity is intended and low correlation (0.22) between capacity expansion (CE) and past utilization $\left(\mathrm{CU}_{\mathrm{L}}\right)$ seems to suggest that under utilization, if any, is mainly of the unintended nature, capacity expansions do not move in line with past utilization rates and it also indicates that abolition of restrictions on licensing due to trade liberalization do not help industry to expand capacity. On the other hand, low correlation (0.19) between capacity expansion (CE) and lagged output $\left(Q_{L}\right)$ indicates that unintended excess capacity is varying from year to year in an unsystematic matter.

\section{Summary and conclusions}

The article tries to assess the utilization efficiency of capacity in terms of econometric framework for the period,1979-80 to 2008-09.The result suggests that there has been declining growth rate of capacity utilization in rubber industry of India during the post reforms period accompanied by declining output growth as well as capacity growth. There exists some excess capacity in the rubber industry which remains unutilized during our study period. The result exhibits that high correlation coefficient between actual output and capacity output for Indian rubber sector implies that major part of under utilization of capacity is intended and low correlation between capacity expansion (CE) and past utilization $\left(\mathrm{CU}_{\mathrm{L}}\right)$ seems to suggest that under utilization, if any, is mainly of the unintended nature, capacity expansions do not move in line with past utilization rates and it also indicates that abolition of restrictions on licensing due to trade liberalization do not help industry to expand capacity. On the other hand, low correlation between capacity 
expansion $(\mathrm{CE})$ and lagged output $\left(\mathrm{Q}_{\mathrm{L}}\right)$ indicates that unintended excess capacity is varying from year to year in an unsystematic matter.

In conclusion, it can be expected that more comprehensible insight is attainable if analysis is conducted on the basis of disaggregated firm level data base.

\section{References}

1. Berndt, E.R. and C. Morrison (1981), Capacity utilization: Underlying economic theory and an alternative approach, American Economic Review, vol. 71, no22, pp 48-52.

2. Berndt,E.R and Hesse, D(1986):Measuring and assessing capacity utilization of manufacturing sectors of nine OECD countries, European Economic Review, vol 30,pp961-89

3. Cassel, J.M. (1937), Excess capacity and monopolistic competition, Quarterly Journal of Economics, vol. 51, pp 426-443.

4. Denny, M, M. Fuss and L Waver man(1981), 'Substitution possibilities for Energy: Evidence from U.S. and Canadian manufacturing Industries in E.R. Berndt and B.C. Field, Modeling and measuring national Resources Substitution (Cambridge M.A., MIT Press).

5. Fare. R., S. Grosskopf, and E.. Kokkelenberg. (1989). "Measuring Plant Capacity, Utilization and Technical Change: A Nonparametric Approach', International Economic Review, 30: 655-666.

6. Färe, R. (1994). "The Existence of Plant Capacity," International Economic Review, 25: 209-213.

7. Friedman. M. (1963), 'More on Archibald versus Chicago', Review of economic studies, vol. 30, pp 65-67.

8. Griliches, Z and Y. Ringstad (1971), Economics of scale and the form of the production function, North Holland, Amsterdam.

9. Hickman, B.G. (1964), 'On a new method of capacity estimation', Journal of the American Statistical Association, vol.59, pp 529-549.

10. Jha, R, Murty, M.N and Satya Paul(1991), Technological change, factor substitution and economies of scale in selected manufacturing industries in India, Journal of Quantitative Economics,vol.7,No.1,pp 165-178.

11. Jorgenson, Dale. W and Zvi Griliches (1967), The explanation of productivity change, Review of Eco- nomic Studies, vol. 34, pp 249-282.

12. Klein, L.R (1960), 'Some theoretical issues in the measurement of capacity', Econometrica, vol.28, no.2, pp272-286.

13. Murty, M.N(1986), Interfuel Substitution and Derived Demands for Inputs in the manufacturing sector of India, Journal of Quantitative Economics, vol.2,No.1,pp119-135.

14. Nelson.R.A (1989), On the measurement of capacity utilization, The Journal of Industrial Economics, vol.XXXVII, March, 1989.

15. Segerson, Katherine and Dale Squires.( 1990). On the Measurement of Economic Capacity Utilization for Multi-Product Industries, Journal of Econometrics, Vol. 44:347-361.

16. Viswanathan, P.K. and G. P. Shivakoti (2005), "Promotion of Rubber Agro Forestry Systems in India: Socio-Economic and Institutional Constraints and Development Potential". Paper presented at the Appraisal Meeting on Improving the Productivity of Rubber Smallholdings through Agro forestry Systems, 5-8 September 2005, Songkhla Province, Thailand. 